Jpn J Electroph $1996 ; 40: 7$

〔Full Paper〕

\title{
The reversible aggregation-disaggregation and fusion of phosphatidylcholine liposomes with and without polyethylene glycol
}

\author{
Toshihiko Ogihara, ${ }^{*}$ Yuji Takamoto, ${ }^{* *}$ Hanako Kumazawa* and Hideo Hayashi***
}

\begin{abstract}
SUMMARY
Aggregation-disaggregation phenomena were observed with light microscopy as functions of the liposome dispersion temperature and the concentration of liposomes which were made of dipalmitoyl phosphatidylcholine in distilled water. Colonies formed by aggregation of the liposomes remaining below the pretransition temperature (about $34^{\circ} \mathrm{C}$ ) disaggregated at the pretransition temperature within $2-10$ $\mathrm{mg} / \mathrm{ml}$ of dipalmitoyl phosphatidylcholine upon heating. Within $15-30 \mathrm{mg} / \mathrm{ml}$, the colonies have disaggregated at the maintransition temperature $\left(42^{\circ} \mathrm{C}\right)$. These phenomena were reversible with respect to temperature. Furthermore, the aggregation and fusion of liposomes have been observed using polyethylene glycols. The abilities for aggregation and fusion, which became stronger with increasing molecular weight or concentration of the polyethylene glycols, were qualitatively observed
\end{abstract}

Key words: dipalmitoyl phosphatidylcholine, liposome, aggregation, fusion, polyethylene glycol.

\section{INTRODUCTION}

There have been some reports on fusion and aggregation of phospholipid liposomes. ${ }^{1,2)}$ These authors ${ }^{1,2)}$ reported that liposomes, which were less than $100 \mathrm{~nm}$ in diameter, irreversibly aggregated at temperatures below the pretransition temperature $\left(\mathrm{Tp}\right.$ : about $34^{\circ} \mathrm{C}^{3)}$ ) or below the maintransition temperature $\left(\mathrm{Tc}: 42^{\circ} \mathrm{C}^{3)}\right.$ ). Wong et al. $^{4)}$ reported that phosphatidylcholine (PC) liposomes, which were $25 \mathrm{~nm}$ in diameter, fused within a few days or a few weeks at temperatures below Tc. However, the aggregation could not be precisely distinguished from the fusion. Also, although the fusion of liposomes by adding PEGs has been studied, ${ }^{5-11)}$ the molecular weights of the PEGs were mainly more than 4000 , and the distinction between aggregation and fusion was also not precise.

The cell fusion technique using polyethylene glycols (PEGs) has been established and applied in various bioscience fields. However, the mechanism of cell fusion has not been fully explained. As a first step in studying the mechanism, we

*荻原利彦，熊澤華子 ; Department of Physiology, Faculty of Hygienic Technology, College of Environmental Health, Azabu University.

** 高本雄治; Plant Engineering Division, Sapporo Breweries Ltd.

*** 林秀生 ; Department of Physiology, Saitama Medical School.

Correspondence address: Toshihiko Ogihara, Department of Physiology, Faculty of Hygienic Technology, College of Environmental Health, Azabu University, 1-17-71, Fuchinobe, Sagamihara 229, Japan.

(Received August 29, 1995, Accepted December 7, 1995, Published February 15, 1996) 
have investigated fusion and aggregation using multilamellar liposomes made of dipalmitoyl phosphatidylcholine (DPPC) and PEGs. On the basis that an irreversible aggregation was fusion, the distinction between fusion and aggregation was observed by light microscopy with changing temperatures. Furthermore, effects of PEGs on the fusion and aggregation were investigated with PEGs of various molecular weights and concentrations.

\section{MATERIALS AND METHODS}

\section{Preparation of DPPC liposomes and addition of PEG solution}

Dipalmitoyl phosphatidylcholine was purchased from Sigma Chemical Co. and used without further purification. Polyethylene glycols (300, $400,600,1000,1500,2000,3000)$ were purchased from Wako Pure Chemical Industries Ltd. Other PEGs(PEG 4000, 6000, 10000, 20000, 50000) were purchased from Merck. All PEGs were of reagent grade.

For preparation of the liposomes, fresh distilled water was added to DPPC in a test tube. After incubating the tube for more than $15 \mathrm{~min}$ at $50^{\circ} \mathrm{C}$, the tube was sonicated for $1 \mathrm{~min}$ above the $\mathrm{Tc}$ for dispersion of the liposomes. The dispersion was kept below the $\mathrm{Tp}$ for more than $15 \mathrm{~min}$ and then used in the experiments. The liposomes were less than $5 \mu \mathrm{m}$ in diameter. Solutions of PEGs were prepared and added to the dispersion immediately before measurement. For removing PEGs, the dispersion was centrifuged for $5 \mathrm{~min}$ at $1000 \mathrm{rpm}$, and then distilled water was added to the precipitation. This operation was repeated several times.

\section{Measurements}

The liposome dispersion was placed in the hollow of a slide glass with a cover glass. The liposomes were observed using an optical microscope (BH-2, Olympus Co.). A thermo-control system, which controlled the temperature of the dispersion, consisted of two thermomodules (CP1.4-71-061, Melcor Co.) for cooling and heating, and a program controller (JP-1231, Chino Co.) with a power supply (GP035-10, Takasago Co.). The cooling and heating scanning speed was set at $1.0^{\circ} \mathrm{C} / \mathrm{min}$, and the temperature of the dispersion was controlled with a precision of \pm $0.2^{\circ} \mathrm{C}$. A video recording system (C-2400, Hamamatsu Photonics Co.) was used to permanently record the results. These systems were controlled by a microcomputer (PC-8801, NEC).

\section{RESULTS}

\section{Reversible aggregation-disaggregation of DPPC liposomes}

Colonies formed by the aggregation of liposomes were observed at temperatures below the Tp within $1-40 \mathrm{mg} / \mathrm{ml}$ of DPPC (Fig. 1(a)). Three phenomena on aggregation and disaggregation were observed with changing DPPC concentrations upon heating and cooling.

At concentrations below $10 \mathrm{mg} / \mathrm{ml}$ of $\mathrm{DPPC}$, upon heating from a temperature below the $\mathrm{Tp}$ to that above the Tc, the colonies were suddenly disrupted and disaggregated to individual liposomes in the neighborhood of the Tp (Fig. 1 (b) and (c)). The disaggregated liposomes moved violently at temperatures above the Tc. The liposomes aggregated and returned to the state of colonies when temperature dropped below the Tp. This reversible aggregation-disaggregation phenomenon was briefly called the $A / D / D$ phenomenon from the three states of the aggregation at temperatures below the $\mathrm{Tp}$, the disaggregation between the Tp-Tc and the disaggregation above the Tc (Fig. 2).

Within $15-30 \mathrm{mg} / \mathrm{ml}$ of DPPC, liposomes remained in the state of aggregation and formed colonies in spite of the temperature being above the Tp. The colonies began to sway at a temperature close to the $\mathrm{Tp}$ and suddenly disaggregated at the $\mathrm{Tc}(\mathrm{A} / \mathrm{A} / \mathrm{D}$ phenomenon). This phenomenon was also reversible. The $A / D / D$ phenomenon was observed again when the concentration was decreased below $10 \mathrm{mg} / \mathrm{ml}$ of DPPC by adding distilled water.

At concentrations above $35 \mathrm{mg} / \mathrm{ml}$ of DPPC, the colonies of liposomes remained even beyond the $\mathrm{Tc}$ and under violent vibration (A/A/A phenomenon). When the DPPC concentration was decreased to $15-30 \mathrm{mg} / \mathrm{ml}$ or below $10 \mathrm{mg} / \mathrm{ml}$ by adding distilled water, the $\mathrm{A} / \mathrm{A} / \mathrm{D}$ phenomenon or the $A / D / D$ phenomenon appeared again, respectively. 
Jpn J Electroph $1996 ; 40: 9$
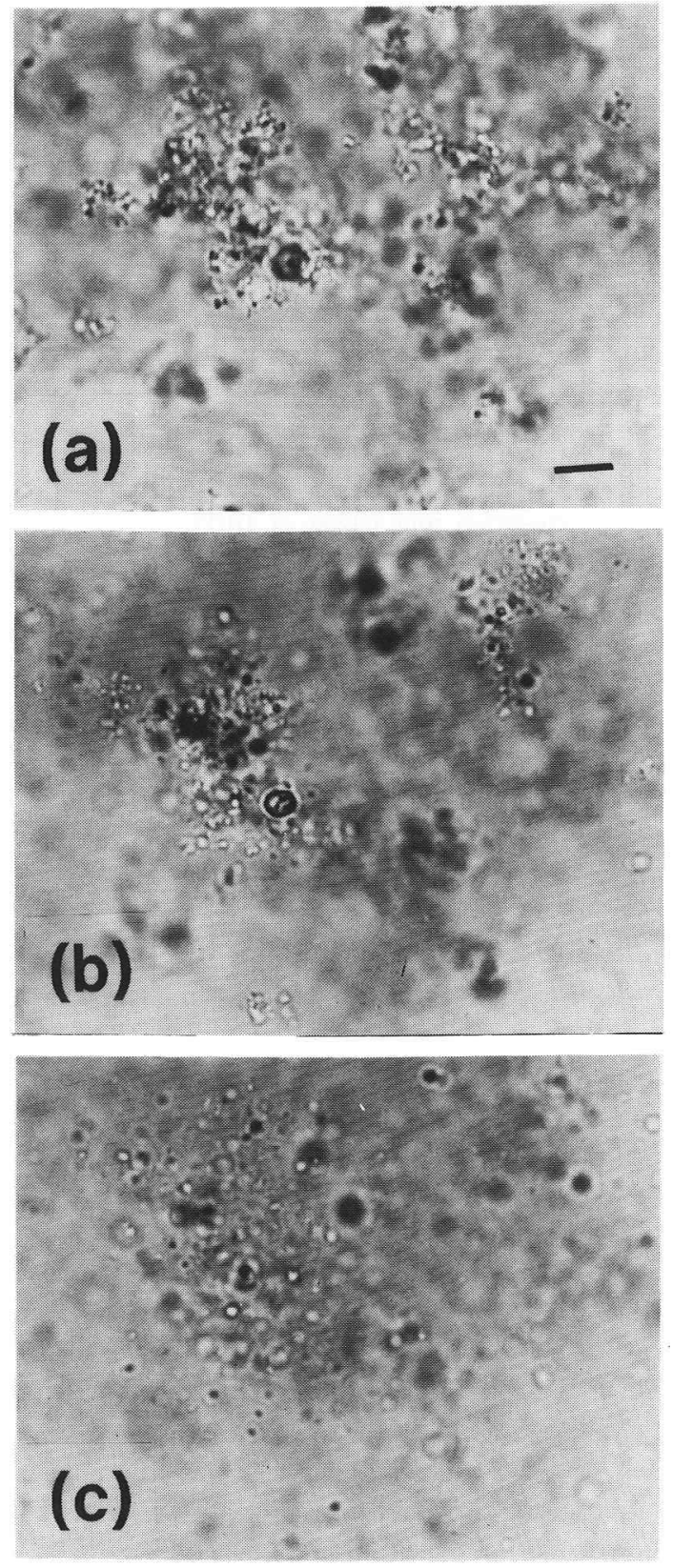

Fig. 1. Light micrographs of DPPC liposomes at 5 $\mathrm{mg} / \mathrm{ml}$ in distilled water upon heating.

(a) colonies of the liposomes at $25.0^{\circ} \mathrm{C}$, ( b ) beginning of disaggregation at $34.1^{\circ} \mathrm{C}, \quad$ (c) liposomes after disaggregation at $36.0^{\circ} \mathrm{C}$ (bar: $10 \mu \mathrm{m}$ ).

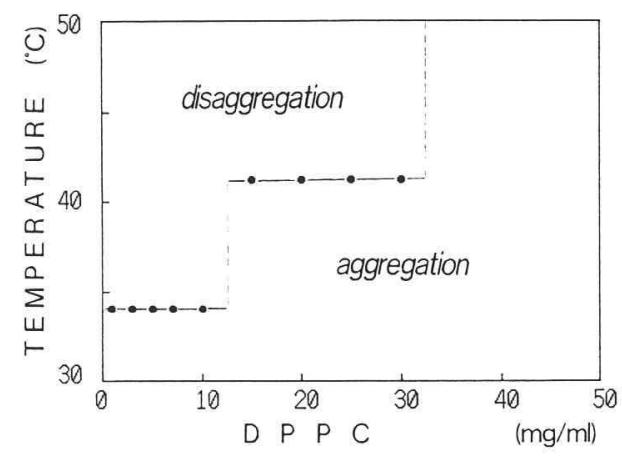

Fig. 2. The aggregation-disaggregation temperature of DPPC liposomes versus the concentration of DPPC upon heating and cooling.

These phenomena shown in Fig. 2 were independent of the heating or cooling scanning speed between 0.1 and $10.0^{\circ} \mathrm{C} / \mathrm{min}$ and were repeatable anytime with the same liposome suspension. Fusions of liposomes have never been observed between $5-70^{\circ} \mathrm{C}$.

Reversible aggregation-disaggregation and fusion with PEGs

The liposome dispersion at around $1 \mathrm{w} / \mathrm{w} \%$ PEG 4000 displayed the $\mathrm{A} / \mathrm{D} / \mathrm{D}$ phenomenon as in the case without PEG 4000 (Fig. 3). The A/A/D phenomenon was observed in $1-2 \mathrm{w} / \mathrm{w} \%$ but the $\mathrm{A} / \mathrm{D} / \mathrm{D}$ phenomenon was recovered by removing PEG 4000. Although the A/A/A phenomenon was observed in $2-10 \mathrm{w} / \mathrm{w} \%$ of PEG 4000 , the $\mathrm{A} / \mathrm{A} / \mathrm{D}$ phenomenon reappeared in the concentration range of $1-2 \mathrm{w} / \mathrm{w} \%$ and also the $\mathrm{A} / \mathrm{D} / \mathrm{D}$ phenomenon did at below $1 \mathrm{w} / \mathrm{w} \%$ by removing the PEG 4000.

At concentrations above $10 \mathrm{w} / \mathrm{w} \%$ PEG 4000, fusion of the liposomes was observed at the Tc with increasing temperature (Fig. 3, Fig. 4( a ) and (b)). Clumps of DPPC which were formed by the fusion remained even below the Tp. Myelin figures ${ }^{12-14)}$ were sometimes formed from the clumps (Fig. 4(b)).

Other PEGs whose molecular weights were smaller than that of PEG 4000 also caused the same phenomena at different concentrations (Fig. 5). Using PEG 600, fusions of liposomes were observed at concentrations above $25 \mathrm{w} / \mathrm{w} \%$. The $\mathrm{A} / \mathrm{D} / \mathrm{D}$ phenomenon was observed below $2 \mathrm{w} / \mathrm{w}$ 


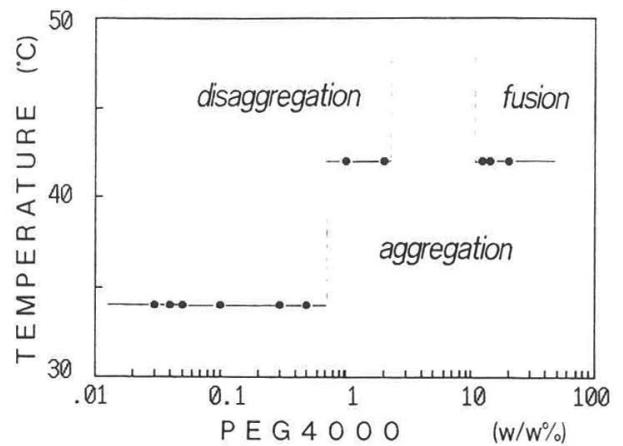

Fig. 3. The disaggregation, aggregation and fusion of DPPC liposomes $(5 \mathrm{mg} / \mathrm{ml})$ versus the concentration of PEG 4000 upon heating.
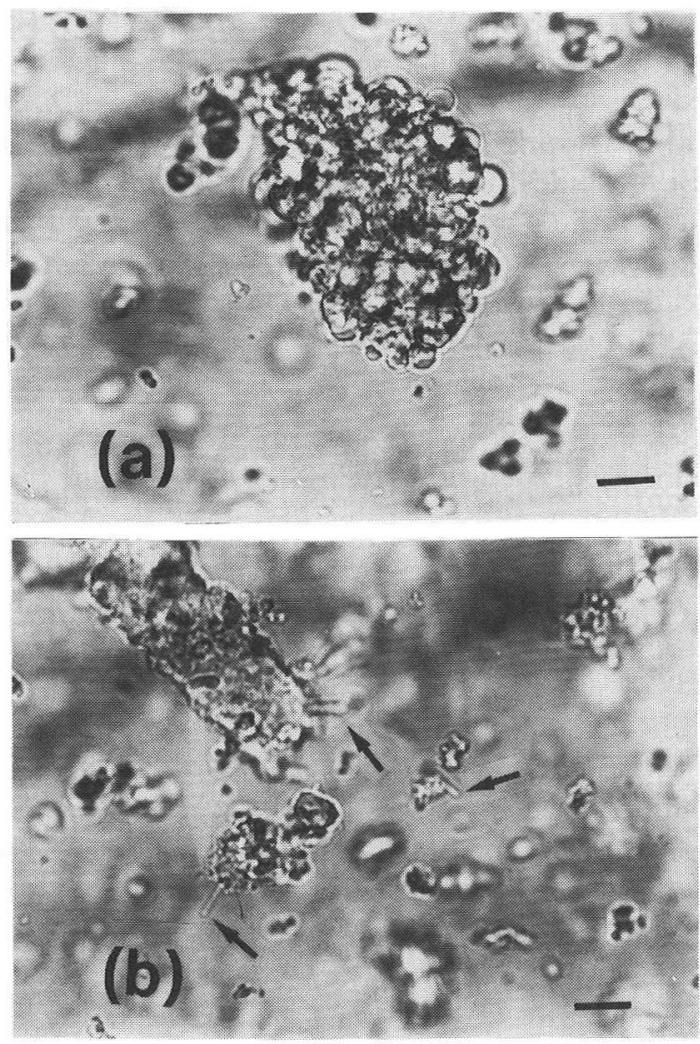

Fig. 4. Light micrographs of the fusion of DPPC liposomes $(5 \mathrm{mg} / \mathrm{ml}$ ) by (a ) $20 \mathrm{w} / \mathrm{w} \%$ and ( b ) 12 w/w \% PEG 4000 at the Tc upon heating. arrow : the position of myelin figure, bar : $10 \mu \mathrm{m}$.

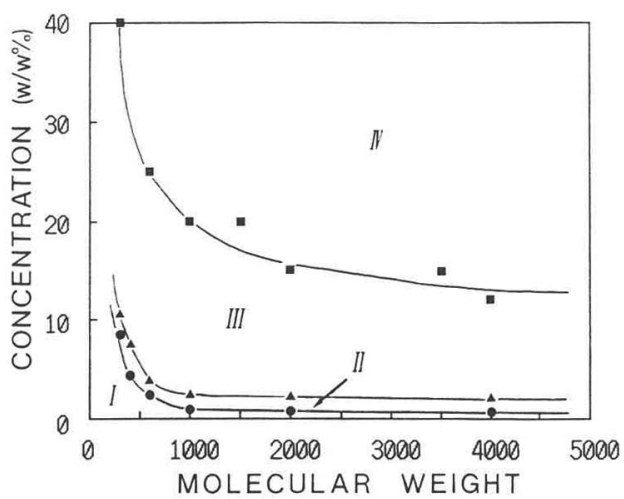

Fig. 5. The concentration of PEGs for aggregation, disaggregation and fusion of DPPC liposomes (5 $\mathrm{mg} / \mathrm{ml}$ ) versus the molecular weights of PEGs upon heating.

The regions of (I) $\mathrm{A} / \mathrm{D} / \mathrm{D}$ phenomenon, (II) $\mathrm{A} / \mathrm{A} / \mathrm{D}$ phenomenon, (III) $\mathrm{A} / \mathrm{A} / \mathrm{A}$ phenomenon and (IV) fusion phenomenon. $\mathrm{A}$ and $\mathrm{D}$ represented aggregation and disaggregation at temperatures below the $\mathrm{Tp}$, the $\mathrm{Tp}$. $\mathrm{Tc}$, above the $\mathrm{Tc}$ in turn, respectively. Symbols $\mathbf{\Delta}$ and were the measured maximum concentration caused the $\mathrm{A} / \mathrm{D} / \mathrm{D}, \mathrm{A} / \mathrm{A} / \mathrm{D}$ and $\mathrm{A} / \mathrm{A} / \mathrm{A}$ phenomenon, respectively.

$\%$, the $\mathrm{A} / \mathrm{A} / \mathrm{D}$ phenomenon was observed within $2-3 \mathrm{w} / \mathrm{w} \%$ and the $\mathrm{A} / \mathrm{A} / \mathrm{A}$ phenomenon was observed within $3-25 \mathrm{w} / \mathrm{w} \%$.

\section{DISCUSSION}

The $\mathrm{Tc}$ and $\mathrm{Tp}$ are investigated by calorimetric studies, ${ }^{3)}$ the ESR method ${ }^{15)}$ and the observation of myelin figure formation. ${ }^{12)}$ Ogihara ${ }^{16)}$ considered that it was possible to determine the $\mathrm{Tc}$ and $\mathrm{Tp}$ with a microscopic observation of liposomes of phosphatidylcholines. We investigated the effects of DPPC concentrations on the phenomena of reversible aggregation-disaggregation and clarified the relationship between DPPC concentrations and the phenomena in this report. The microscopic observation of liposomes thus provides an easy, rapid and sensitive method for the determination of the $\mathrm{Tc}$ and $\mathrm{Tp}$ of phosphatidylcholines.

It is said that the surface potential of phosphatidylcholine (PC) liposomes is usually electrically neutral. Tatulian ${ }^{17)}$ reported that the surface potential of liposomes which were made of 
dimyristoyl phosphatidylcholine (DMPC) became slightly negative at the $\mathrm{Tc}$ with increasing temperature at a low concentration of potassium salts. If the change in the surface potential is caused by structural exchange of a PC molecule at the $\mathrm{Tc}$, it can not explain our results only by a potential change at the $\mathrm{Tc}$, because there are two states at temperatures above the $\mathrm{Tc}$; one is an aggregation state in the $\mathrm{A} / \mathrm{A} / \mathrm{A}$ phenomenon and the other one is a disaggregation state in the $A$ / $\mathrm{D} / \mathrm{D}$ or the $\mathrm{A} / \mathrm{A} / \mathrm{D}$ phenomenon (Fig. 2).

It has been reported that liposomes which were less than $100 \mathrm{~nm}$ in diameter fused at temperatures below the $\mathrm{Tp}^{1,2,4)}$ On the other hand, we have observed the aggregation of liposomes (less than $5 \mu \mathrm{m}$ in diameter) at temperatures below the Tp but have never observed the fusion at temperatures below the $\mathrm{Tp}$, between the $\mathrm{Tp}-\mathrm{Tc}$ or above the Tc. The small liposomes (diameters of $25 \mathrm{~nm}^{4)}$ and less than $100 \mathrm{~nm}^{1,2)}$ ) presumably contained many unilamellar liposomes, so that their liposomes may be easily fused. However, these authors ${ }^{1,2,4)}$ did not precisely distinguish fusion from aggregation.

A PEG concentration which was a boundary between the $A / D / D$ phenomenon and $A / A / D$ phenomenon and also a boundary between the A/ $\mathrm{A} / \mathrm{D}$ phenomenon and $\mathrm{A} / \mathrm{A} / \mathrm{A}$ phenomenon did not change with a PEG of more than 1000 in molecular weight but increased with decreasing molecular weight of the PEG which was less than 1000 (Fig. 5). The PEG concentration which caused fusion of DPPC liposomes became lower with PEGs of higher molecular weight (Fig.5). Thus, it was confirmed that the abilities for aggregation and fusion were stronger with increasing molecular weight or concentration of PEG.

Finally, we propose that it will be important to pay attention to the distinction between fusion and aggregation when studying the mechanism of cell or membrane fusion.

\section{REFERENCES}

1) Suurkuusk J, Lenz BR, Barenholz $Y$, Biltmen RL, Thompson TE. A calorimetric and fluorescent probe study of the gel-liquid crystalline transition in small, single-lamellar dipalmitoylphosphatidylcholine vesicle. Biochemistry 1976 ; 15 : 1393-401.

2) Watts A, Marsh D. Saturation transfer ESR studies of molecular motion in phosphatidylglycerol bilayers in the gel phase. Effect of pretransition and $\mathrm{pH}$ titration. Biochim Biophys Acta 1981 ; 642 : 231-41.

3) Hinz HJ, Sturtevant JM. Calorimetric studies of dilute aqueous suspensions of bilayers formed from synthetic L- $\alpha$-lecithins. J Biol Chem 1972 ; 247, 6071-5.

4) Wong M, Anthony FH, Tillac TW, Thompson TE. Fusion of dipalmitoylphosphatidylcholine vesicles at $4{ }^{\circ} \mathrm{C}$. Biochemistry $1982 ; 21: 4126^{-}$ 32.

5) Honda K, Maeda Y, Sakakawa S. The components contained in polyethylene glycol of commercial grade (PEG-6,000) as cell fusion. Biochem Biophys Res Commun 1981; 101: 165-71.

6) Tilcock CPS, Fisher D. The interaction of phospholipid membranes with poly (ethylene glycol) vesicle aggregation and lipid exchange. Biochim Biophys Acta 1982; 688: $645-52$.

7) Morgan CG, Thomas EW, Yianni YP. The use of fluorescence energy transfer to distinguish between poly(ethylene glycol)-induced aggregation and fusion of phospholipid vesicles. Biochim Biophys Acta 1983; 828: 356-62.

8) Boni LT, Hah JS, Hui SW, Mukherjee P, Ho JT, Jung CY. Aggregation and fusion of unilamellar vesicles by poly (ethylene glycol). Biochim Biophys Acta 1984 ; 775 : 409-18.

9) Tadolini B, Varani E, Cabrini L. The influence of poly(ethylene glycol) 6000 on supermine-induce aggregation of liposomes. Biochem J 1986 ; 236 : 651-5.

10) Papahadjopoulos D, Portis A. Calcium-induce lipid phase transition and membrane fusion. Ann NY Acad Sci 1978; 308: 50-66.

11) Makins JF, Holt G. Liposome-mediated transformation of streptomycetes by chromosomal DNA. Nature 1981; 293: 671-3.

12) Mishima K, Satoh K. Myelin forms of phospholipids. Forma $1989 ; 4$ : 103-21.

13) Mishima $K$, Ogihara $T$, Tomita $M$, Satoh $K$. Growth rate of myelin figures for phosphatidylcholine and phosphatidylethanolamine. Chem Phys Lipid 1992; 62 : 87-91.

14) Sakurai I, Suzuki T, Sakurai S. Structure and growth behavior of myelin figures. Mol Cryst Liq Cryst 1990 ; 180B : 305-11. 
生物物理化学 $1996 ； 40 ： 12$

15) Shimshick EJ, McConnell HM. Lateral phase separation in phospholipid membranes. Biochemistry $1973 ; 12$ : 2351-60.

16) Ogihara $T$. Temperature dependence on the reversible aggregation-disaggregation phenomenon of lecithin liposomes (in Japanese).
J Saitama Med School 1988 ; 15 : 211-9.

17) Tatulian SA. Effect of lipid phase transition on the binding of anions dimyristoylphosphatidylcholine liposomes. Biochim Biophys Acta $1983 ; 736$ : 189-95. 